\title{
A trajetória dos programas de transferência de renda no Brasil: o impacto da variável federativa
}

\section{Introdução}

O objetivo deste artigo é retratar a trajetória dos programas de transferência de renda no sistema de proteção social brasileiro, procurando demonstrar como algumas questões federativas têm afetado decisivamente a sua implementação, desde as primeiras iniciativas subnacionais até a adoção de programas nacionais com clara interface intergovernamental.

A partir da análise do apoio financeiro da União aos programas municipais de garantia de renda mínima associados a ações socioeducativas, autorizado pela Lei no 9.533/1997, do Programa Nacional de Renda Mínima vinculada à educação - "Bolsa Escola", instituído pela Lei nº 10.219/2001, e do Programa Bolsa Família, criado pela Lei no ${ }^{10.836 /}$ 2004, procurar-se-á identificar os fatores que determinaram o aperfeiçoamento dos programas de transferência de renda do Governo Federal.

$\mathrm{O}$ argumento central é que o modelo federativo influenciou diretamente o desenvolvimento dos programas de transferência de renda no Brasil e foi determinante para o seu bom desempenho. Este trabalho visa a enriquecer a atual discussão sobre o melhor caminho para a reestruturação de nosso sistema de proteção social, tendo em vista que a redução da pobreza e da desigualdade social, além de fundamental para a democracia, é estratégica para a obtenção de desenvolvimento real e sustentado.

Elaine Cristina

Lício é

Especialista em Políticas

Públicas e

Gestão

Governamental,

Chefe de

Gabinete da

ENAP Escola

Nacional de

Administração

Pública e

Mestre em

Administração

Pública e

Governo pela

EAESP/FGV.

Contato:

elaine.licio@

enap.gov.br 


\section{Breve histórico dos programas de transferência de renda no Brasil}

Há relativo consenso de que um dos maiores desafios brasileiros, se não o maior, está na redução dos históricos e altos índices de pobreza e desigualdade. São cerca de 50 milhões de pobres, cuja renda é insuficiente para alimentação, moradia, transporte e vestuário. Desse total, mais de 20 milhões são indigentes que não recebem sequer o suficiente para ingerir alimentos em quantidade mínima necessária à vida saudável e produtiva (BARROs, 2000). É esse o problema que as políticas de transferência de renda buscam minimizar.

A proposta de inclusão social viabilizada pela concessão de benefício monetário aos membros de uma comunidade como forma de distribuição da renda é defendida tanto pelos liberais clássicos, preocupados com a autonomia das pessoas e a liberdade de expressão (FRIEDMAN, 1962), quanto pelas correntes ideológicas da esquerda, preocupadas com a equiidade, a distribuição de recursos, as desigualdades sociais e a necessidade de fortalecer valores comunitários (VAN PARIJS, 1992). No mundo inteiro, o tema tem sido tratado sob diversas formas, adquirindo maior força nos últimos 20 anos, dada a crise do welfare state e os novos rumos do capitalismo.

No Brasil, a discussão foi fortalecida em 1991, quando o Senador Eduardo Suplicy apresentou projeto de lei que instituía um programa de renda mínima para o país. Em 1995, o Distrito Federal foi palco da primeira experiência brasileira de renda mínima vinculada à educação, quando então recebeu o nome de Bolsa Escola. Na mesma época, Campinas e Ribeirão Preto instituíram um programa de renda mínima, porém vinculado à assistência social. Segundo Lena Lavinas (2000), foi a primeira vez que um programa social alcançou escala e cobertura capaz de gerar impacto efetivo na população carente, tradicionalmente desprezada pelas políticas públicas.

A crescente visibilidade das experiências localizadas de renda mínima estimulou a apresentação de diversos projetos de lei com o objetivo de generalizar essas experiências em todo o território nacional, resultando na aprovação da Lei no 9.533/97, que instituiu o Programa Renda Mínima, autorizando a União a co-financiar (em 50\%) programas de garantia de renda mínima municipais associados a ações socioeducativas, reconhecendo tanto a fragilidade financeira do município ao providenciarlhe aporte de recursos, quanto sua maior facilidade em executar programas de redução da pobreza, pela maior proximidade dos beneficiários.

Com a Lei no 10.219/2001, o Governo Federal instituiu o novo programa de renda mínima vinculada à educação, chamado Bolsa Escola, que veio substituir o Renda Mínima, em vigor até janeiro de 2001. O novo 
programa ampliou o anterior, abrangendo $100 \%$ dos municípios e trazendo

diversas alterações na forma de financiamento, gestão e distribuição dos recursos. O advento do Bolsa Escola e de outros programas, como o Bolsa Alimentação, o Auxílio-Gás e o Programa de Erradicação do Trabalho Infantil (PETI), além da criação de uma ferramenta de gestão - o Cadastro Único -, que reuniu num banco de dados as informações sobre os beneficiários desses programas, foi aos poucos consolidando a opção do governo brasileiro por políticas de transferência de renda como estratégia de combate à pobreza e à desigualdade social.

A eleição do Presidente Lula, em 2002, com base em programa de governo com forte apelo social, fortaleceu ainda mais a opção pelos programas de transferência de renda. Todavia, a avaliação do novo governo foi de que, embora esses programas tivessem representado avanço nas políticas sociais brasileiras, eles praticamente ignoraram a existência de programas similares conduzidos por estados e/ou municípios, não conseguindo superar problemas tradicionais, como a pulverização de recursos, o elevado custo administrativo, as superposições de públicos-alvo, a competição entre instituições, a ausência de coordenação e de perspectiva intersetorial (Cohn; FonsecA, 2004).

Assim, a partir de articulação interministerial, coordenada pela CasaCivil da Presidência da República, formulou-se novo programa, chamado Bolsa Família (Lei no $10.836 / 2004$ ), para unificar os procedimentos de gestão e execução das ações de transferência de renda do Governo Federal, especialmente as do Programa Nacional de Renda Mínima vinculada à educação - Bolsa Escola (Lei no 10.219/2001), do Programa Nacional de Acesso à Alimentação - PNAA (Lei no 10.689/2003), do Programa Nacional de Renda Mínima vinculada à saúde - Bolsa Alimentação (Medida Provisória no 2.206-1/2001), do Programa Auxílio-Gás (Decreto no 4.102/2002) e do Cadastramento Único do Governo Federal (Decreto no 3.877/2001).

Além disso, destaca-se, no início de 2003, a criação do Programa Fome Zero, um conjunto de políticas públicas de combate à fome e às suas causas estruturais, garantindo a segurança alimentar de todos os brasileiros (CARTILHA, 2003). Essa articulação intersetorial também deu origem ao Ministério do Desenvolvimento Social e Combate à Fome (Lei no ${ }^{\circ}$ 10.869/ 2004), que abrange as atribuições do Ministério da Assistência Social e do Ministério Extraordinário da Segurança Alimentar e Combate à Fome.

Dessa forma, verificou-se que o sistema de proteção social brasileiro sofreu forte reorientação pela adoção das políticas de transferência de renda no período recente. Inicialmente adotada pelos governos subnacionais, essas políticas agora são capitaneadas pelo Governo Federal, influenciando e sendo influenciadas diretamente pelo nosso modelo federativo. Para análise 
mais qualificada desse processo, convém retomar brevemente o que vem sendo discutido em termos de padrões de relações intergovernamentais na implementação das políticas sociais no Brasil.

\section{Relações intergovernamentais e políticas sociais: três vertentes principais}

O federalismo influencia diretamente o desenvolvimento das políticas sociais. Entretanto, a forma como isso acontece depende especificamente do modelo federativo adotado, bem como da disposição das instituições em determinado contexto político (PAUL PIERson, 1995).

No Brasil, o processo de descentralização descoordenado que se iniciou no período da redemocratização, aliado ao padrão predominante de relações intergovernamentais predatório e não cooperativo, fez que as políticas sociais fossem tradicionalmente independentes, sobrepostas, pulverizadas e apenas modestamente coordenadas. O fortalecimento da democracia e a descentralização promovida pela Constituição de 1988 proporcionaram maior autonomia política, administrativa e fiscal para as instâncias subnacionais. Por estarem mais próximos da população, os municípios tiveram que administrar demanda cada vez maior por políticas sociais, o que desencadeou expressivo processo de inovação dessas políticas em âmbito local, sobretudo municipal (ARRETCHE, 1996). Foi esse o contexto em que surgiram os primeiros programas de transferência de renda em nosso país.

Segundo Abrucio e Ferreira Costa (1999), há leque variado de opções relativas ao padrão ideal de relações intergovernamentais na implementação das políticas sociais no Brasil.

Uma primeira vertente é favorável a algum tipo de federalismo mais ou menos cooperativo, no qual as tarefas de planejamento e coordenação global cabem ao Governo Federal; as de planejamento e coordenação regional, aos governos estaduais e a implementação, aos municípios e/ou empresas privadas e/ou organizações não governamentais. A avaliação das políticas seria responsabilidade das três esferas de governo, cada uma procurando identificar, em sua área de competência, obstáculos legais, políticos, sociais, deficiências técnico-administrativas, relação custo/ benefício, etc. O financiamento das políticas deve ser compartilhado entre as três esferas de governo, visando aos princípios da equiidade social garantia de condições mínimas de existência para todos - e do equilíbrio federativo, com a perspectiva de redução gradativa das desigualdades econômicas regionais, sem perda de autonomia política e com respeito às diferenças sociais e culturais entre as regiões do país.

Outra vertente, mais dualista, considera a autonomia política e tributária dos governos locais e, portanto, a responsabilidade fiscal e a 
liberdade de iniciativa no campo das políticas públicas, derivada dessa autonomia - como os principais elementos estimuladores do desenvolvimento socioeconômico e do amadurecimento político dos municípios. A grande desigualdade de renda entre regiões e municípios tenderia a ser reduzida pelo estímulo à mobilização das potencialidades locais, fruto da necessidade de "competir" por recursos tanto do setor privado quanto dos governos federal e estaduais, que reduziriam as transferências automáticas de receitas, substituindo-as por transferências "condicionadas" ao desempenho fiscal e à eficácia das políticas sociais implementadas pelos municípios.

Uma terceira vertente, ainda restrita aos meios acadêmicos, procura articular o modelo "vertical" de relações intergovernamentais, exemplificado pela primeira vertente, com o modelo "horizontal", característico da segunda vertente. Desse modo, em vez de fragmentar as políticas, como no modelo "competitivo", ou segmentá-las, como no "verticalizante", o modelo, denominado de coordenação cooperativa, propõe a criação de instâncias intergovernamentais de planejamento, coordenação e avaliação de políticas sociais em cada uma das esferas de governo. Dependendo do nível do governo responsável pela execução da política, as respectivas instâncias teriam perfil mais "vertical", isto é, envolveriam as três esferas, como no caso de políticas nacionais, ou mais "horizontal", que implica a participação de vários governos de mesmo nível - estadual ou municipal - ou, então, de representantes dos dois níveis subnacionais. Como se pode perceber, esse modelo permite a composição de instâncias governamentais com os mais variados perfis, flexibilizando bastante o processo de decisão num sistema federativo.

É com base nas perspectivas analisadas de cada uma dessas vertentes que se passará à compreensão do padrão de relações intergovernamentais predominante na implementação dos programas Renda Mínima, Bolsa Escola e Bolsa Família. Estes foram selecionados por serem os mais representativos de interferências no arranjo federativo, do ponto de vista da abrangência do público-alvo e dos recursos alocados, e refletirem as várias estratégias e alternativas de adoção do papel de coordenação da União na promoção dessas políticas no Brasil. Para melhor contextualização, segue-se um quadro-resumo das principais dimensões desses programas. Em seguida, passar-se-á à análise mais minuciosa de cada um deles. 
Quadro-Resumo das principais dimensões dos programas analisados

\begin{tabular}{|c|c|c|c|}
\hline & $\begin{array}{l}\text { Renda Mínima } \\
\text { em jan/2001 }\end{array}$ & $\begin{array}{l}\text { Bolsa Escola } \\
\text { em out/2002 }\end{array}$ & $\begin{array}{l}\text { Bolsa Família } \\
\text { em abril/2004 }\end{array}$ \\
\hline $\begin{array}{l}\text { Perfil do } \\
\text { público-alvo }\end{array}$ & $\begin{array}{l}\text { Famílias com } \\
\text { crianças de } 7 \text { a } \\
14 \text { anos matri- } \\
\text { culadas no Ensino } \\
\text { Fundamental }\end{array}$ & $\begin{array}{l}\text { Famílias com } \\
\text { crianças de } 6 \text { a } 15 \\
\text { anos matriculadas } \\
\text { no Ensino Funda- } \\
\text { mental }\end{array}$ & $\begin{array}{l}\text { Famílias em } \\
\text { situação de extre- } \\
\text { ma pobreza e } \\
\text { em situação de } \\
\text { pobreza com } \\
\text { crianças e jovens } \\
\text { entre } 0 \text { e } 16 \text { anos } \\
\text { incompletos }\end{array}$ \\
\hline $\begin{array}{l}\text { Renda per capita } \\
\text { mensal mínima }\end{array}$ & $\begin{array}{l}\text { 1/2 salário mínimo } \\
(\mathrm{R} \$ 130,00 \mathrm{em} \\
\text { agosto/2004) }\end{array}$ & $\mathrm{R} \$ 90,00$ & $\begin{array}{l}\text { Extrema pobreza } \\
(\mathrm{R} \$ 50,00) \\
\text { Pobreza } \\
(\mathrm{R} \$ 100,00)\end{array}$ \\
\hline $\begin{array}{l}\text { Famílias } \\
\text { beneficiadas }\end{array}$ & 1 milhão & 5,1 milhões & 4,1 milhões \\
\hline $\begin{array}{l}\text { Meta do público- } \\
\text { alvo (n⿳ํ de famílias) }\end{array}$ & --- & 5,7 milhões & 11,4 milhões \\
\hline $\begin{array}{l}\text { Volume de recur- } \\
\text { sos aportados } \\
\text { pela União }\end{array}$ & $\mathrm{R} \$ 162,7$ milhões & $\mathrm{R} \$ 2,2$ bilhões & $\mathrm{R} \$ 5,3$ bilhões \\
\hline $\begin{array}{l}\text { Forma de repasse } \\
\text { dos recursos }\end{array}$ & $\begin{array}{l}\text { Do FNDE para o } \\
\text { FNAS, que, por } \\
\text { sua vez, repassava } \\
\text { às prefeituras por } \\
\text { meio de conta } \\
\text { específica }\end{array}$ & $\begin{array}{l}\text { Direto ao } \\
\text { beneficiário }\end{array}$ & $\begin{array}{l}\text { Direto ao } \\
\text { beneficiário }\end{array}$ \\
\hline $\begin{array}{l}\text { Valor médio do } \\
\text { benefício, por } \\
\text { família }\end{array}$ & $\mathrm{R} \$ 38,58$ & $\mathrm{R} \$ 27,73$ & $\mathrm{R} \$ 72,80$ \\
\hline $\begin{array}{l}\text { № de municípios } \\
\text { beneficiados }\end{array}$ & 1.624 & 5.536 & 5.461 \\
\hline $\begin{array}{l}\text { Participação dos } \\
\text { estados }\end{array}$ & Nenhuma & Nenhuma & $\begin{array}{l}\text { Alguma, sobre- } \\
\text { tudo na Gestão } \\
\text { do Cadastro } \\
\text { Único }\end{array}$ \\
\hline $\begin{array}{l}\text { Responsável } \\
\text { pelo controle das } \\
\text { condicionalidades }\end{array}$ & Municípios & $\begin{array}{l}\text { União, mediante } \\
\text { informação dos } \\
\text { municípios }\end{array}$ & $\begin{array}{l}\text { Em definição, } \\
\text { com a tendência } \\
\text { de descentraliza- } \\
\text { ção desta tarefa } \\
\text { aos municípios }\end{array}$ \\
\hline
\end{tabular}




\section{Apoio financeiro da União aos programas municipais de garantia de renda mínima associados a ações socioeducativas - Lei no 9.533/97}

Essa lei autorizava a União a co-financiar, com 50\%, programas municipais de renda mínima vinculados à educação. Para tanto, os programas deviam atender a famílias com renda per capita de até 1/2 salário mínimo e filhos ou dependentes de 7 a 14 anos, desde que se encontrassem matriculados e freqüentando regularmente escolas públicas. $\mathrm{O}$ valor do benefício por família definia-se pela seguinte fórmula:

$\mathrm{R} \$ 15,00 \mathrm{X}$ (número de crianças por família) - 0,5 X (renda per capita)

Como contrapartida do município e do estado no financiamento do programa, a lei permitia a utilização de recursos destinados à assistência socioeducativa, em horário complementar ao da freqüência no Ensino Fundamental para os filhos e dependentes das famílias beneficiárias, mas dava preferência aos municípios que destinassem pelo menos $50 \%$ dos seus recursos à assistência financeira às famílias. $\mathrm{O}$ montante repassado pelo Governo Federal deveria obrigatoriamente ser transferido em espécie para as famílias beneficiárias.

A lei previa que o apoio da União aos programas municipais seria estendido gradualmente de 1998 até 2002. Dessa forma, a cada ano seriam apoiadas prioritariamente as iniciativas daqueles municípios mais carentes, identificados pelo Instituto de Pesquisa Econômica (IPEA), obedecendose ao limite de $25 \%$ do total desses municípios existentes em cada estado da Federação, até que, em 2002, todos os municípios passíveis de ajuda fossem beneficiados. A partir de então, havendo disponibilidade de recursos e considerando-se os resultados do programa, poderia o Poder Executivo estender a abrangência do programa para todos os municípios e o Distrito Federal.

O Renda Mínima durou menos de dois anos. A Lei no 9.533, que o instituiu em 10 de dezembro de 1997, só foi regulamentada pelo Decreto no 2.609 , em 3 de junho de 1998, e sua implementação só teve início efetivamente a partir de março de 1999. Assim foi até fevereiro de 2001, quando deu lugar ao Bolsa Escola. Apesar de seu período relativamente curto de vigência, faz-se necessária uma análise das principais críticas sofridas, que, em certa medida, foram responsáveis pela sua transformação no Bolsa Escola federal. 
Favorecimento aos municípios mais ricos?

Além do baixo valor do benefício, $\mathrm{R}$ \$38,58 em média, por família, outras críticas fizeram-se a essa iniciativa. A primeira referia-se à limitação do apoio federal aos municípios com receita corrente por habitante e renda familiar per capita inferior à respectiva média estadual, o que, segundo estimativas de Amaral (1998), excluía cerca de 40\% dos municípios brasileiros. Outra crítica referia-se ao estabelecimento de percentual fixo de $50 \%$ para a repartição das despesas entre o Governo Federal e os municípios, sem considerar os desníveis na capacidade financeira. Vale lembrar que cada município, isoladamente ou em conjunto com o estado, deveria responsabilizar-se pelos outros $50 \%$.

Segundo Amaral (1998), na prática, a alocação de subsídios da forma descrita beneficiaria apenas os municípios para os quais os custos totais dos programas não ultrapassassem $20 \%$ de suas receitas correntes. Trata-se de municípios que, em sua maioria, situam-se nas regiões mais ricas do país (Sudeste e Sul). Isso significa que, além de não contemplar a maioria dos potenciais beneficiários dos programas de renda mínima, a adoção desse critério resultaria numa distribuição perversa do ponto de vista inter-regional, beneficiando as regiões mais ricas em detrimento das mais pobres.

O principal problema do percentual fixo de $50 \%$ para o co-financiamento dos custos totais do programa pelo Governo Federal reside no fato de não se levarem em conta as disparidades na capacidade de financiamento dos municípios. Esse percentual fixo não altera em nada essas disparidades, fazendo o valor dessa contribuição ficar freqüientemente aquém ou além do montante efetivamente necessário para o financiamento do programa.

\section{Balanço preliminar: o incentivo a mudanças}

Dada a "permanente" escassez de recursos do Governo Federal para programas sociais, essa lei propiciou "saudável competição" entre os municípios que, por sua vez, somente eram contemplados, se implementassem um bom programa de renda mínima vinculado a ações socioeducativas. Essa competição aumentou a possibilidade de inovações e aperfeiçoamento do Renda Mínima. Além disso, o fato de a União prover $50 \%$ do orçamento fazia que os municípios se motivassem a destinar mais recursos de sua receita tributária para esse programa, na seguinte perspectiva: quanto maior sua contrapartida, maior o repasse federal, possibilitando maior transferência de renda às famílias pobres, aquecimento do comércio local e aumento da arrecadação tributária. 
Ao atribuir ao Governo Federal o repasse de recursos para que os municípios viabilizassem a execução do programa, esta iniciativa reconhecia a incapacidade financeira destes, individualmente, promovendo certa uniformização de tratamento, embora o regime de alíquota fixa impedisse que essa uniformização fosse plena. Além disso, por se tratar de convênio, cada município ou estado interessado deveria individualmente prover esforços para ser admitido pelo programa.

O Renda Mínima orientava-se, portanto, por um padrão dualista ou competitivo de relações intergovernamentais, na medida em que valorizava a autonomia dos entes federativos e estimulava o envolvimento destes mediante a vinculação do volume de recursos repassados ao montante da contrapartida do município, sem fixar transferências automáticas independentes do desempenho municipal. Todavia o desenho do programa não demonstrou possuir incentivos suficientes para concretizar a participação dos estados. Em seu breve período de existência, não houve um único convênio firmado nesse sentido.

Esse diagnóstico, aliado à perspectiva de destinação de mais recursos para as políticas de combate à pobreza, bem como à proximidade das eleições presidenciais na época, entre outros motivos, levaram o Governo Federal a ampliar o programa.

Em janeiro de 2001, havia 1.624 municípios conveniados com o Ministério da Educação (MEC), implementando o Renda Mínima com repasses da União da ordem de $\mathrm{R} \$ 162,7$ milhões por ano e 1,03 milhão de famílias beneficiárias (RELATÓRIO, 2002). Em fevereiro, tal programa foi suspenso, dando lugar a outro, mais abrangente, denominado Programa Nacional de Renda Mínima vinculada à educação - Bolsa Escola, instituído pela Lei no 10.219/2001. Vejamos as principais mudanças trazidas pelo Bolsa Escola, bem como as condições que favoreceram seu surgimento.

\section{O Programa Nacional de Renda Mínima vinculada à educação - Bolsa Escola - Lei no 10.219/2001}

Em abril de 2001 foi promulgada a Lei no 10.219 , substituindo o Programa Renda Mínima e introduzindo sensíveis mudanças no desenho dessa política, que, a partir de então, passou a ser conhecida como Bolsa Escola. Nesse novo formato, o Governo Federal responde por 100\% dos recursos transferidos aos beneficiários, cabendo aos municípios o cadastramento das famílias e o controle da freqüência dos alunos. Essa orientação está de acordo com a vertente de inspiração cooperativa ou vertical do padrão de relações intergovernamentais na implementação de 
políticas sociais, na medida em que define, segmenta e distingue as atribuições desses dois entes federativos para o alcance dos objetivos do programa, que inclui ainda, como se verá a seguir, a participação da sociedade civil por meio de um conselho de controle social.

Uma das principais mudanças no Bolsa Escola em relação ao Renda Mínima está na ampliação da faixa etária do público-alvo, ou seja: de 7 a 14 anos para 6 a 15 anos, o que ampliou aos alunos a oportunidade de conclusão do Ensino Fundamental.

A suplementação mensal de renda varia de $\mathrm{R} \$ 15,00$ a $\mathrm{R} \$ 45,00$ por família, de acordo com o número de crianças. O pagamento está condicionado a $85 \%$ de frequiência dos filhos às aulas, verificada a cada três meses. As mães recebem um cartão magnético da Caixa Econômica Federal com o qual o benefício é retirado no banco, casa lotérica, agência dos Correios ou estabelecimentos credenciados, sem nenhum tipo de intermediação. No cálculo da renda familiar per capita $(\mathrm{R} \$ 90,00$, fixados pelo Decreto no 4.313/2002), são computados os rendimentos auferidos por todos os membros da família, incluídos os benefícios concedidos por programas federais, bem como por programas estaduais e municipais de complementação de renda. Todavia o Bolsa Escola veda expressamente a inclusão de famílias beneficiadas pelo Programa de Erradicação do Trabalho Infantil (PETI), enquanto permanecerem nessa condição².

No antigo programa, o repasse de recursos ao Fundo Nacional do Desenvolvimento da Educação (FNDE) era feito pelo Fundo Nacional de Assistência Social (FNAS), órgão vinculado ao Ministério da Previdência e Assistência Social. Celebrados os convênios entre o FNDE e os municípios, os recursos eram transferidos às prefeituras para conta específica, aberta no Banco do Brasil. Assim, durante os dois primeiros anos do Programa Renda Mínima, coube aos municípios estabelecer os procedimentos a serem adotados para o pagamento dos benefícios, bem como indicar o agente pagador: bancos, tesouraria, escola, etc. Por vezes, tantos procedimentos davam causa ao atraso no recebimento dos benefícios pelas famílias.

Graças ao Fundo de Combate à Pobreza ${ }^{3}$, toda a população-alvo foi incluída. Em 2002, o Bolsa Escola contou com recursos da ordem de R\$ 2,2 bilhões. Com base nos dados fornecidos pelo IBGE (Censo 1991), o Governo Federal elaborou um planejamento para verificar os potenciais beneficiários, no intuito de calcular os custos de "universalização" dessa política. Foi assim que se chegou ao número de 5,7 milhões de famílias e 10,7 milhões de crianças beneficiárias, que satisfaziam os requisitos legais, ou seja, pertenciam a famílias com renda per capita de até $1 / 2$ salário mínimo e crianças de 6 a 15 anos de idade, matriculadas regularmente no Ensino Fundamental e distribuídas pelo território nacional. 


\section{Descontinuidade no pagamento}

dos benefícios

Embora tenha representado grande acréscimo ao nosso sistema de proteção social, a mudança do Programa Renda Mínima para o Programa Bolsa Escola deu causa à interrupção na distribuição dos benefícios, comprometendo os resultados sociais positivos que a política vinha alcançando. Em janeiro de 2001, foram distribuídos os últimos benefícios do Renda Mínima. Já em fevereiro foi editada a Medida Provisória no 2.140, que instituiu o novo formato, denominado Bolsa Escola. Em abril essa medida provisória foi convertida na Lei n⿳⺈⿴囗十一 10.219/2001 e, em maio, foi então editado o Decreto no 3.823/2001, que regulamenta a mencionada lei. Foi só a partir de junho de 2001 que os benefícios voltaram a ser distribuídos. É bem provável que essa solução de continuidade de seis meses, no mínimo, possa ter comprometido o ano escolar de milhões de crianças que dependiam do benefício para poder freqüentar a escola em 2001.

De toda forma, resolvido o problema do gerenciamento dos recursos, agora centralizados no Governo Federal e repassados diretamente aos beneficiários, foi necessário pensar numa questão mais complexa, ou seja, como inibir comportamentos predatórios dos municípios, a quem cabia a execução do Programa ${ }^{4}$. Por isso, na Lei no $10.219 / 2001$, foram previstos alguns instrumentos de controle, acompanhamento e fiscalização, de forma a coordenar responsabilidades, sobre os quais se discorrerá a seguir.

\section{Inibindo comportamentos predatórios}

A Lei no 10.219/2001 previu formas de acompanhamento, controle e fiscalização do programa municipal. Uma delas foi a obrigação de constituir um conselho de controle social do Programa Bolsa Escola, com, no mínimo, 50\% de representantes não vinculados à administração municipal. Entre suas competências está a responsabilidade pela aprovação da relação de famílias cadastradas, bem como a avaliação e a fiscalização da aplicação correta de todas as regras do programa. Além disso, pode-se contar com a colaboração da Pastoral da Criança na fiscalização do programa nos mais de 2.000 municípios em que atua, o que constitui reforço ao controle social necessário para garantir a qualidade do cadastro das famílias.

Ao exigir a criação de conselhos municipais como contrapartida do repasse de recursos para o financiamento dos programas, o Governo Federal rompe, pelo menos potencialmente, o monopólio do Poder Executivo local sobre o processo decisório em áreas cada vez mais relevantes do ponto de vista do impacto orçamentário, como a educação. Não é fortuito que uma das maiores dificuldades à consolidação das políticas sociais, em nível local e estadual, seja a resistência de prefeitos e 
governadores em ceder poder e recursos financeiros aos conselhos e fundos municipais responsáveis pela definição de diretrizes e financiamento dessas políticas.

Para celebrar o convênio com o MEC, os municípios devem obrigatoriamente instituir, mediante lei municipal, um programa de renda mínima vinculado a ações socioeducativas, nos padrões exigidos pela Lei no 10.219 / 2001. O custeio e o gerenciamento dessas ações socioeducativas são de responsabilidade do próprio município que, inclusive, pode suplementar o benefício. Este regime de co-responsabilidade dotou o Governo Federal de instrumentos necessários para agir com rigor contra os maus administradores. Constatadas as irregularidades no cadastramento dos beneficiários, por exemplo, o prefeito pode ser responsabilizado e o repasse federal da cota da prefeitura no Fundo de Participação dos Municípios (FPM) pode ser suspenso, além de responder a ação de improbidade administrativa.

A exigência da legislação municipal é a própria garantia dessa co-responsabilidade. Por meio dela, o município compromete-se, inibindo comportamentos predatórios, tais como: o cadastro de famílias "fantasmas", o filho do prefeito recebendo o benefício, apadrinhados, etc. Cabe aos conselhos municipais contribuir para fiscalização do programa, mas a responsabilidade é do prefeito. Portanto, pelo menos, institucionalmente, o Governo Federal conta com instrumentos razoáveis para o acompanhamento, controle e fiscalização do programa.

\section{Novos incentivos a mudanças}

Os impactos dessa política na melhoria das condições de vida e dos indicadores sociais em âmbito local dependem, sobretudo, de parcerias que agreguem recursos financeiros e humanos em sua implementação. Essa orientação está de acordo com a vertente cooperativa ou vertical do padrão de relações intergovernamentais na implementação de políticas sociais, na medida em que incentiva o compartilhamento do financiamento da política entre os entes federativos das três esferas de governo. A União contribui com o que pode, dando o "pontapé" inicial, ao fornecer condições mínimas para o início do programa. Cabe aos estados e municípios dar ao programa continuidade e incrementá-lo na medida de suas possibilidades. A questão é como incentivá-los para esse papel colaborativo.

Em dezembro de 2002, momento de transição de governo, dos 5.561 municípios brasileiros havia 5.536 integrados ao Bolsa Escola, concedendo apoio financeiro a cerca de 5,1 milhões de famílias pobres para que mantivessem seus filhos na escola (RELATóRIo, 2002).

Tendo em vista o diagnóstico dos programas de transferência de renda realizado pela equipe de transição do novo governo, bem como a 
necessidade de unificação deles, iniciou-se longo processo de discussão

interministerial, liderado pela Casa Civil da Presidência da República, no qual se discutiram o modelo e as estratégias adotadas para essa unificação. Esse processo culminou com o compromisso pela inclusão social entre o Governo Federal, os estados e o Distrito Federal, firmado em setembro de 2003, com o objetivo de conferir maior racionalidade, organicidade e efetividade às ações de combate à fome e à pobreza, de emancipação das famílias e de promoção do desenvolvimento sustentável das comunidades (SINOPSE, 2003). O desenho do programa Bolsa Família, que será analisado a seguir, foi o principal resultado deste processo.

\section{Programa Bolsa Família - Lei $n^{-} \mathbf{1 0 . 8 3 6 / 2 0 0 4}$}

O Bolsa Família surgiu com a finalidade de unificar os procedimentos de gestão e execução das ações de transferência de renda do Governo Federal, especialmente as do Programa Nacional de Renda Mínima vinculada à educação - Bolsa Escola (Lei no 10.219/2001), do Programa Nacional de Acesso à Alimentação - PNAA (Lei no 10.689/ 2003), do Programa Nacional de Renda Mínima vinculada à saúde - Bolsa Alimentação (Medida Provisória no 2.206-1/2001), do Programa AuxílioGás (Decreto no 4.102/2002) e do Cadastramento Único do Governo Federal (Decreto no $3.877 / 2001$ ).

Trata-se de um programa de transferência de renda destinado a famílias com renda per capita de até $\mathrm{R} \$ 100,00$ mensais, que associa a transferência do benefício financeiro a condicionalidades que garantem o acesso aos direitos sociais básicos - saúde, alimentação, educação e assistência social. Ele foi criado para atender a duas finalidades básicas: combater a miséria e a exclusão social e promover a emancipação das famílias mais pobres. Para 2004 a previsão é de um orçamento de R \$ 5,3 bilhões (BolsA FAmíLIA, 2004).

Os programas anteriores, inclusive o Bolsa Escola, funcionando inteiramente separados uns dos outros, tinham diferentes cadastros de beneficiários, e parte significativa das famílias estava inscrita em apenas um programa. Algumas famílias recebiam mais de um benefício e famílias vizinhas, em condições iguais, nada recebiam. Embora já se houvesse instituído, no final de 2001, a ferramenta do Cadastro Único com o objetivo de unificar os cadastros de beneficiários dos diversos programas de transferência de renda do Governo Federal, sua implementação era ainda inexpressiva e seu modelo de gestão, indefinido. É importante ressaltar que a unificação não elimina as razões que levaram à criação desses programas. Os objetivos de cada programa estão mantidos, mas agora de acordo com 
lógica mais ampla e concepção integral de políticas sociais. O programa unificado continuará mantendo as crianças na escola, fazendo acompanhamento das gestantes, monitorando a nutrição das crianças, etc.

Diferentemente dos programas anteriores, que focavam o indivíduo, o Bolsa Família inovou ao privilegiar a família. Essa opção baseia-se no fato de que os programas de transferência de renda não constituem um fim em si mesmos, em que pese sua importância como mecanismo de alívio imediato da pobreza. Eles devem estar obrigatoriamente associados a políticas complementares que criem possibilidades reais de que essas famílias, ao se desvincularem do programa, tenham condições de prover o próprio sustento, superando a condição de exclusão social.

Segundo o Ministério de Desenvolvimento Social (Bolsa FAmília, 2004), as famílias elegíveis são compostas por dois grupos: famílias em situação de extrema pobreza, com renda mensal per capita de até R\$ 50,00 e famílias pobres e extremamente pobres com crianças e jovens entre 0 e 16 anos incompletos, com renda mensal de até $\mathrm{R} \$ 100,00$ per capita.

O programa oferece dois tipos de benefícios: o básico e o variável. O benefício básico é concedido a famílias em situação de extrema pobreza. $\mathrm{O}$ valor desse benefício é fixo, de R \$ 50,00 mensais, independentemente da composição e do número de membros do grupo familiar. O benefício variável, no valor mínimo de $\mathrm{R} \$ 15,00$, será concedido a famílias pobres e extremamente pobres que tenham, sob sua responsabilidade, crianças e adolescentes na faixa de 0 a 16 anos incompletos, até o teto de três benefícios por família, ou $\mathrm{R} \$ 45,00$. As famílias em situação de extrema pobreza poderão acumular o benefício básico e o variável, chegando ao máximo de $\mathrm{R} \$$ 95,00 mensais ( $\mathrm{R} \$ 50,00$ do benefício básico mais $\mathrm{R}$ \$ 45,00 do benefício variável). As famílias em situação de pobreza, com renda entre $\mathrm{R} \$ 51,00$ e $\mathrm{R} \$ 100,00$, podem receber até $\mathrm{R} \$ 45,00$. A celebração de parcerias com o Governo Federal permite que esses valores sejam complementados por estados e municípios.

Quem já é beneficiário de algum dos programas anteriores está automaticamente cadastrado no Bolsa Família e deve aguardar sua inclusão, que dependerá de vários fatores: pactuação entre União, estados e municípios, disponibilidade de vagas no estado ou município, expansão de recursos orçamentários, etc. Todavia, até o beneficiário ser incluído no novo programa, ele continua recebendo normalmente seus benefícios.

A inclusão no Cadastro Único é uma pré-condição para as famílias participarem do programa. Quem não é beneficiário de nenhum programa, portanto não está incluído no Cadastro Único, deve aguardar seu cadastramento pela prefeitura. A meta é incluir, gradualmente, as 11,4 milhões de famílias que atendem aos critérios de elegibilidade, até o final de 2006.

O Governo Federal e as prefeituras são co-responsáveis pela inclusão de novas famílias no Cadastro Único. A União assegura suporte técnico 
aos municípios que executam o cadastramento cujo controle social, ou seja, a validação, deve ser local. Ao contrário do procedimento adotado anteriormente, a base de dados do Cadastro Único será compartilhada com estados e municípios, pois o objetivo é o aprimoramento do planejamento das políticas públicas em todos os níveis: federal, estadual e municipal.

Em abril de 2004, o Bolsa Família beneficiava 5.461 municípios, atingindo 4,1 milhões de famílias. O valor médio do benefício é de R\$ 72,80 , sendo que a maior parte dos beneficiários - 59\% - encontra-se na Região Nordeste, a mais carente do país (Programas, 2004).

\section{Gestão do programa e os papéis dos entes federativos}

O programa é coordenado pelo Conselho Gestor Interministerial (CGI), composto pelos ministros da área social que administra os atuais programas de transferência de renda e também pelos ministros do Planejamento e da Fazenda, além do ministro-chefe da Casa Civil. A Secretaria Executiva é o braço operativo do CGI e coordena a operacionalização do programa no que diz respeito às funções de cadastro, pagamento de benefícios, monitoramento e avaliação. A exemplo do que já ocorre com a maioria das ações federais descentralizadas, o programa contará com instância de controle social local, que deverá ser composta por representantes do setor público e da sociedade civil, de forma paritária.

O Governo Federal considera fundamental o papel dos estados. Sua participação pode envolver desde o apoio técnico e logístico para a execução do programa nos municípios até a sua efetiva coordenação, dependendo dos interesses e da disponibilidade de recursos de cada estado. Além de apoiar a implementação do programa, os governos estaduais devem indicar um interlocutor para dar início ao processo de negociação, articulação e concertação com o Governo Federal, bem como apoiar os municípios no processo de cadastramento.

De acordo com o modelo de gestão descentralizada, os governos municipais são os principais gestores do programa com as famílias, por meio de unidade de coordenação, que deverá articular os diversos órgãos e entidades locais afetos ao programa, interagir com a Secretaria Executiva, com a Caixa e com os governos estaduais, além de atender diretamente aos beneficiários potenciais e atuais do Bolsa Família. Para tanto, deverão estruturar uma equipe multissetorial de coordenação do programa com as condições necessárias para sua operação (estrutura física e logística), assegurando a oferta de serviços essenciais de saúde, educação, acompanhamento alimentar e nutricional para viabilizar o cumprimento das condicionalidades pelas famílias beneficiárias. Essa coordenação é ainda responsável pela manutenção do cadastro, pela 
capacitação de profissionais envolvidos, pela avaliação de desempenho e do impacto do programa no município e pela informação periódica sobre o cumprimento das condicionalidades à Secretaria Executiva do programa e aos ministérios setoriais.

Municípios e estados também devem promover a articulação das ações para assegurar o caráter intersetorial do programa, além de viabilizar a oferta de ações complementares, com vistas a criar meios e condições de promover a emancipação das famílias beneficiárias, tais como programas de requalificação e qualificação profissional, políticas de microcrédito e economia solidária. Eles colaboram inclusive com o Poder Judiciário na redução do sub-registro civil e na emissão de documentação para as famílias, além de apoiar os conselhos estaduais e municipais, a fim de garantir o controle social do programa.

\section{A caminho de padrão de "coordenação cooperativa" das relações intergovernamentais}

O desenho alcançado pelo Bolsa Escola articula incentivos à cooperação na busca pela maximização de seus objetivos e resultados. Um deles, garantido pela legislação, diz respeito à suspensão dos repasses do Fundo de Participação dos Municípios (FPM), no caso de cadastramento fraudulento por parte do município. Essa é, na grande maioria das vezes, a maior fonte das receitas municipais no atual modelo federativo brasileiro (em média $40 \%$ a $60 \%$ da receita total), de modo que suspendê-la inviabiliza a administração municipal. Esse mecanismo evita os problemas decorrentes da distância entre o "principal" (Governo Federal) e o "agente" (governos municipais), induzindo este último a proceder com lisura na manutenção dos cadastros e acompanhamento dos beneficiários.

Além de proporcionar alívio imediato da pobreza e acesso efetivo aos direitos sociais básicos, a implementação do Bolsa Família contribui enormemente para a manutenção do nosso pacto federativo, tendo em vista seu impacto redistributivo regional. Segundo Fonseca e Cohn (2004), em dezembro de 2003 as transferências realizadas pelo Bolsa Família representaram para a Região Norte o equivalente a $15 \%$ dos recursos provenientes do FPM; para a Nordeste, 28\%; para a Sudeste, 10\%; para a Sul, 8\%; e para a Centro-Oeste, $7 \%$, beneficiando as regiões com maior número de pobres. Esse aporte massivo de recursos, provendo as necessidades mais básicas e imediatas da população pobre, possibilita aos governos subnacionais investirem mais recursos próprios em políticas complementares de favorecimento à emancipação da família, dotando-a de condições de prover o próprio sustento com dignidade. 
O Programa Bolsa Família firmou termo de cooperação com os Estados de Minas Gerais e do Rio de Janeiro (Bolsa FAmília, 2004), contemplando as atribuições e responsabilidades enumeradas há pouco. Em Minas Gerais, o instrumento visou ainda à ampliação do atendimento dos beneficiários do Programa Bolsa Familia para a educação, financiada pelo governo estadual, os quais passarão também a ser atendidos gradativamente pelo Bolsa Família.

No Estado do Rio de Janeiro, a cooperação foi mais além. O estado compromete-se a complementar com R $\$ 10,00$ os benefícios pagos pela União a 176 mil famílias beneficiárias do Bolsa Família, em 20 municípios, inclusive a capital. Os municípios poderão participar dessa cooperação mediante termo específico. Além disso, o cartão de recebimento dos benefícios terá um layout acordado com a União. Institui-se ainda um Grupo Executivo Tripartite como instância de deliberação da cooperação, tendo como competências imediatas o planejamento e o acompanhamento do cadastramento das famílias beneficiárias, bem como a definição da sistemática de gestão local do Programa Bolsa Família. Deve ser previsto um sistema de monitoramento e avaliação do Programa Bolsa Família no estado, assegurada a articulação com órgãos federais, estaduais e municipais responsáveis pelo planejamento, pesquisa e avaliação das políticas sociais.

O Município do Rio de Janeiro, por sua vez, resolveu aderir à cooperação com o estado, adicionando mais $\mathrm{R} \$ 10,00$ aos benefícios pagos pela União às famílias beneficiárias do Bolsa Família residentes na cidade, atingindo inicialmente as 80 mil famílias, que também receberão o complemento de $\mathrm{R} \$ 10,00$ pelo governo estadual.

Essas são as primeiras iniciativas concretas de cooperação mais estreita entre União, estados e municípios para implementação de políticas de transferência de renda, as quais estão de acordo com o padrão da coordenação cooperativa de relações intergovernamentais na implementação de políticas sociais. Como mencionado anteriormente, esse modelo permite a composição de instâncias governamentais com os mais variados perfis, flexibilizando bastante o processo decisório num sistema federativo. A criação de instâncias intergovernamentais de planejamento, coordenação e avaliação de políticas sociais, como o Grupo Executivo Tripartite no Estado do Rio de Janeiro, vai ao encontro da flexibilidade necessária para a implementação mais efetiva de uma política que visa a combater um problema de grande complexidade, como a pobreza no Brasil, que possui múltiplas dimensões, muito além da insuficiência de renda.

Ainda é cedo para dizer se esse será o padrão adotado, pois as iniciativas concretizadas são poucas e de funcionamento recente. Todavia, segundo o Ministério do Desenvolvimento Social (Bolsa FAmília, 2004), estão em curso diversas negociações com estados e municípios, alguns dispostos a elevar os valores dos benefícios (Goiás, Distrito Federal, Mato 
Grosso do Sul), outros garantindo um piso mínimo de $\mathrm{R} \$ 50,00$ ou $\mathrm{R} \$ 60,00$ para as famílias beneficiárias do programa (São Paulo, Acre, Amazonas e Roraima). O que é certo é o amplo reconhecimento de que, sem os esforços coordenados e integrados das três esferas de governo, não será possível a redução da pobreza e da desigualdade social no Brasil. Assim, o lançamento do Bolsa Família foi adiado por quase um mês, porque o Presidente preferiu, antes de lançá-lo, reunir todos os governadores em setembro de 2003 (SINOPSE, 2004), quando foi firmado o compromisso pela maior racionalidade, organicidade e efetividade das ações de inclusão social.

\section{Controle das condicionalidades: um sistema ainda frágil}

Embora essa análise preliminar seja positiva para que o Bolsa Família alcance seus objetivos de médio e longo prazo, deve-se atentar para o controle das condicionalidades. Elas são o ponto forte desse programa e o diferenciam da mera "esmola", que alivia a situação de privação temporária. As condicionalidades são ações que as famílias devem obrigatoriamente observar para que possam permanecer no programa, garantindo o acesso a direitos que, a médio e longo prazo, aumentam a autonomia das famílias na perspectiva da inclusão social. O Bolsa Família manteve as seguintes condicionalidades previstas nos programas que unificou:

- acompanhamento de saúde e do estado nutricional das famílias: todos os membros da família beneficiária devem participar do acompanhamento de saúde, principalmente gestantes, nutrizes e crianças de 0 a 6 anos. (Programa Nacional de Renda Mínima vinculado à saúde - Bolsa Alimentação - Medida Provisória no2.206-1/2001);

- frequiência à escola: todas as crianças em idade escolar, de 6 a 15 anos, devem estar matriculadas e freqüentando o Ensino Fundamental. (Programa Nacional de Renda Mínima vinculada à educação - Bolsa Escola - Lei no 10.219/2001);

- educação alimentar: todas as famílias beneficiárias devem participar de ações de educação alimentar oferecidas pelo Governo Federal, estadual e/ou municipal (Programa Nacional de Acesso à Alimentação PNAA - Lei no 10.689/2003).

Os ministérios são os responsáveis pelo acompanhamento das condicionalidades, como já vinha ocorrendo nos programas existentes. As informações recolhidas pelos ministérios nesse acompanhamento são repassadas trimestralmente à Secretaria Executiva do Bolsa Família, que consolida as informações. A frequiência à escola é acompanhada pelas Secretarias Municipais de Educação a partir do sistema desenvolvido pelo MEC. O acompanhamento de saúde é realizado pelas Secretarias Municipais de Saúde a partir dos agentes comunitários. 
A verificação da frequiência dos alunos às aulas é provavelmente um dos pontos mais críticos do programa unificado hoje. Embora o monitoramento da saúde e do estado nutricional das famílias beneficiárias do Bolsa Família esteja sendo bem realizado, a verificação da freqüência em sala de aula dos alunos beneficiados pelo Bolsa Família não tem sido feita de forma satisfatória.

Ela vinha sendo realizada a cada três meses desde 2002. Na verdade, o sistema utilizado para tanto está passando por uma reformulação. Enquanto isso, o acompanhamento tem sido feito nos moldes antigos: a Caixa Econômica Federal envia formulários às prefeituras para que as escolas respondam ao MEC se as crianças beneficiadas estão ou não comparecendo às aulas.

A idéia é de que, até o final de 2004, um novo sistema esteja pronto e a responsabilidade desse monitoramento seja descentralizada para estados e municípios. Com isso, a possibilidade de retirar as famílias do programa por não-cumprimento das contrapartidas exigidas também caberá às administrações locais. Hoje isso ainda é atributo exclusivo do Governo Federal. Entretanto, de Brasília é praticamente inviável que ele tome decisões sobre uma criança que não foi à escola. É o gestor local quem pode buscar soluções para que a criança que saiu da escola tenha condição de retornar.

As condicionalidades do Bolsa Escola passaram a ter acompanhamento apenas no terceiro trimestre de 2002, quando $62 \%$ dos municípios atendidos à época responderam o questionário. No último trimestre do ano passado, o acompanhamento do governo atingia $90 \%$ das cidades beneficiadas e $13 \%$ das escolas (Constantino, 2004). O dilema desse modelo advém do fato de que muitos municípios não conseguem informar a freqüência escolar por falta de capacitação de seus gestores ou por dificuldade de acesso à tecnologia da informação. Portanto, suspender o pagamento aos beneficiários que não conseguem encaminhar a informação sobre a freqüência, conforme prevê a lei, pode significar dupla punição a esses municípios mais carentes.

\section{Considerações finais}

Na dinâmica dos programas de transferência de renda na Federação brasileira, os atores principais foram, num primeiro momento, os governos municipais, responsáveis pelo surgimento dessa inovação governamental. Num segundo momento, foi a União quem desempenhou papel fundamental para a profusão dos programas nos municípios mais pobres do país, funcionando como "catalisadora" dessas iniciativas municipais, sobretudo do ponto de vista financeiro, por meio do Programa Renda Mínima, adotando um padrão dualista ou competitivo de relações intergovernamentais. 
Com a implementação do Bolsa Escola e, posteriormente, do Bolsa Família, a União definitivamente apropriou-se do papel coordenador e indutor da participação dos demais entes federativos na implementação desses programas, dando origem a um padrão cooperativo ou vertical, que tem caminhado rumo à coordenação cooperativa das relações intergovernamentais. Para que o Bolsa Família se concretize, há de incentivar-se a construção de redes e a ação regionalizada, principalmente entre municípios das regiões metropolitanas onde a questão da inclusão social exige ainda mais soluções coordenadas. Uma sugestão seria a adoção de consórcios que reunissem os recursos físicos e financeiros dos respectivos municípios para a gestão coordenada do programa.

Quanto aos governos estaduais, importa destacar que, no início, predominou sua indefinição relativa à participação na gestão e financiamento dos programas, ficando praticamente ausentes. Embora até o advento do Bolsa Família não se tinham verificado nos programas federais mecanismos institucionais expressivos que incentivassem a cooperação estadual, vemos agora concretizarem-se novos arranjos institucionais que favorecem a cooperação desses entes federativos, fruto principalmente da disposição de os três níveis de governo articularem-se para combater a pobreza e a desigualdade social.

Não obstante, ao longo deste trabalho, ter-se procurado demonstrar que o resgate da dívida social brasileira não depende apenas da identificação de política social efetiva, é igualmente fundamental criar condições institucionais para seu bom desempenho. Embora os desafios para o aperfeiçoamento do Bolsa Família sejam enormes, sobretudo na questão do controle das condicionalidades, a trajetória do programa tem demonstrado que elas não são insuperáveis. Seu desenho, validado pelos governos estaduais e construído a partir do diálogo baseado no reconhecimento da intersetorialidade no âmbito do Governo Federal, confere-lhe maior legitimidade e sustentabilidade.

É sabido que, na busca de melhor arranjo federativo, também para a implementação das políticas sociais, o melhor caminho é a criação de jogo de responsabilidades mútuas, e não apenas de distribuição de perdas e benefícios entre União, estados e municípios. Nesse sentido, constatouse no Bolsa Família a tentativa de combinar-se o que há de melhor na centralização - repartição de recursos e assistência técnica - com os aspectos positivos da descentralização - a possibilidade de "inovação" e maior controle social, dada sua maior proximidade da população. Esse padrão de relacionamento intergovernamental tem grande potencial de favorecer a redução das desigualdades regionais, garantindo, a um só tempo, os sentimentos de autogoverno e esperança de simetria entre os participantes da Federação, pelo menos no que concerne à implementação dessa política social. 
1 De acordo com o MEC, esta vedação justifica-se em virtude da concepção dos programas. O Bolsa Escola atua de forma preventiva ao trabalho infantil; é ex ante. Já o PETI busca resgatar as crianças do trabalho infantil, procurando remediar a situação; é, portanto, expost.

2 Instituído pela Emenda Constitucional no 31/2000 e com duração prevista para 10 anos, o Fundo é formado por parte da arrecadação de impostos e contribuições federais.

3 Típico dilema da ação coletiva relativa à teoria do agente $\mathrm{x}$ principal, segundo a qual devese criar mecanismos capazes de garantir que o agente, no caso o município, aja de acordo com os interesses e objetivos do principal, que no caso é o Governo Federal.

\section{Referências bibliográficas}

Abrucio, Fernando Luiz; Ferreira Costa, Valeriano Mendes. Reforma do Estado e o contexto federativo brasileiro. São Paulo: Fundação Konrad Adenauer, (Pesquisas, oㅡ 12), 1999.

Amaral, Carlos et al. Programas de Renda Mínima e Bolsa Escola: concepção, gestão e financiamento. Planejamento e Políticas Públicas, Brasília: IPEA, v. 2, p. 4-58, 1998.

Arretche, Marta. Mitos da descentralização: mais democracia e eficiência nas políticas públicas? Revista Brasileira de Ciências Sociais, São Paulo, ano 11, n. 31, p. 44-66, 1996.

BARros, Ricardo Paes et al. Evolução recente da pobreza e da desigualdade: marcos preliminares para a política social no Brasil. In: Pobreza e Política Social. São Paulo: Cadernos Adenauer, 끈 1, 2000.

Bolsa Família: Disponível em: <http://www.fomezero.gov.br/ContentPage. aspx?filename=pfz_4001.xml> Acesso em: 27 jul. 2004

CARTILHa da Mobilização Social do Fome Zero. Ministério do Desenvolvimento Social. Disponível em: <http://www.fomezero.gov.br/download/Cartilha\%20Fome\%20Zero\% 202004\%20-\%20final.pdf > Acesso em: 30 jul. 2003.

Cohn, Amélia; Fonseca, Ana. O Bolsa Família e a questão social. Teoria e Debate, São Paulo, n 57, mar./abr. 2004.

Constantino, Luciana. Governo deixa de fiscalizar exigência do Bolsa-Família. Folha de $S$. Paulo. Disponível em: <http://www1.folha.uol.com.br/folha/dimenstein/noticias gd060704.htm> Acesso em: 25 jul. 2004.

Friedman, Milton. Capitalism and freedom. Chicago: University of Chicago Press, 1962.

Lavinas, Lena (Coord.). Avaliação do Programa Bolsa-Escola de Recife. Relatório Final, Convênio ILO Banco Mundial, ANPEC/IPEA, out. 2000.

Programas Sociais do Governo Lula: avaliação e perspectivas. Disponível em: <http:// www.presidencia.gov.br/casacivil/foruns/static/arquivos/Bolsa\%20Família.ppt>Acesso em: 23 jul. 2004.

Pierson, Paul. Fragmented Welfare States: Federal Institutions and Development of Social Policy. Governance, Cambridge, v. 8, n. 4, 1995. 
Relatório de Atividades do Programa Nacional de Bolsa Escola. Brasília: Ministério da Educação, 2002.

SINOPSE - Resumo dos jornais. Jornal do Brasil. Disponível em: <http://www.radiobras. gov.br/anteriores/2003/sinopses_0110.htm> Acesso em: 30 jul. 2004.

VAn PARIJS, Philippe (Ed.). Arguing for a basic income. London: Verso, 1992. 


\section{A trajetória dos programas de transferência de renda no Brasil: o impacto da variável federativa \\ Elaine Cristina Lício}

Neste trabalho, analisa-se a trajetória dos programas de transferência de renda no sistema de proteção social brasileiro, procurando demonstrar como algumas questões federativas têm afetado decisivamente a sua implementação, desde as primeiras iniciativas subnacionais até a adoção de programas nacionais com clara interface intergovernamental. $\mathrm{O}$ argumento central é que o modelo federativo influenciou diretamente o desenvolvimento dos programas de transferência de renda no Brasil, sendo determinante para o seu bom desempenho.

La trayectoria de los programas de transferencia de ingresos en Brasil: el impacto de la variable federativa

\section{Elaine Cristina Lício}

En este trabajo se analiza la trayectoria de los programas de transferencia de ingresos en el sistema de protección social brasileño, buscando demostrar como algunas cuestiones federativas han afectado de manera decisiva su puesta en práctica, desde las primeras iniciativas subnacionales hasta la adopción de programas nacionales con clara interfaz intergubernamental. El argumento central es que el modelo federativo ha influenciado directamente el desarrollo de los programas de transferencia de ingresos en el Brasil, siendo determinante para o su buen desempeño.

\section{The trajectory of income-transfer programmes in Brazil: the impact of the federative variable}

\section{Elaine Cristina Lício}

This paper analyses the trajectory of income-transfer programmes within the Brazilian social-protection system, trying to demonstrate how some federative issues have decisively affected their implementation, from the very first sub-national initiatives to the adoption of national programmes having a clear intergovernmental interface. The central line of argument is that the federative model has directly influenced the development of incometransfer programmes in Brazil, being determinant for their good performance.
Revista do

Serviço

Público

Ano 55

Número 3

Jul-Set 2004

Elaine Cristina

Lício é

Especialista

em Políticas

Públicas e

Gestão

Governamental,

Chefe de

Gabinete da

ENAP Escola

Nacional de

Administração

Pública e

Mestre em

Administração

Pública e

Governo pela

EAESP/FGV.

Contato:

elaine.licio@

enap.gov.br 